\title{
A malformed oriental garden lizard Calotes versicolor from north-east Bangladesh
}

\author{
ASHIS KUMAR DATTA ${ }^{1 *} \&$ MD. KAMRUL HASAN ${ }^{2}$ \\ ${ }^{1}$ University of East Anglia, Norwich, NR4 7TJ, UK \\ ${ }^{2}$ Department of Zoology, Jahangirnagar University, Savar, Dhaka-1342, Bangladesh \\ *Corresponding author e-mail: ashisdattaju@gmail.com
}

$T^{\text {he }}$ he oriental garden lizard, Calotes versicolor (Daudin, 1802) (Fig. $1 \mathrm{~A}$ ) is a widely-distributed agamid species found across the Indian subcontinent, Afghanistan, Iran, Thailand, Vietnam, Cambodia, Laos, Indonesia, Singapore and southern China (Das, 2010; Hasan et al., 2014; Uetz et al., 2019). In Bangladesh, C. versicolor inhabits a wide range of habitats, including dry and moist forest, near human habitation, parks, forest edges and roadside vegetation (Khan, 2008; Hasan et al., 2014; Khan, 2015; IUCN Bangladesh, 2015).
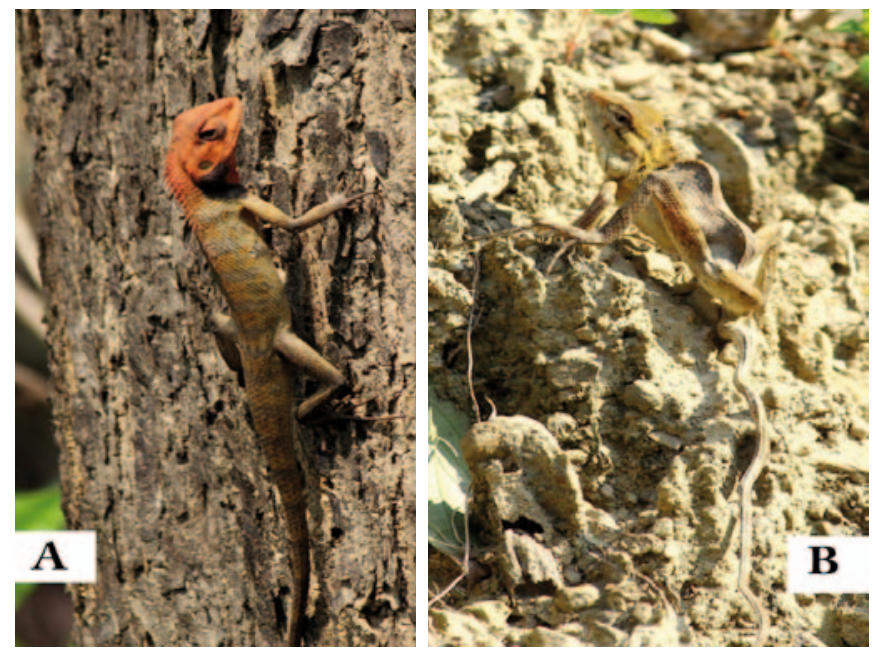

Figure 1. The oriental garden lizard (C. versicolor) from north-eastern Bangladesh A. Normal adult male, B. Deformed female from the same area

This note describes a single malformed specimen of $C$. versicolor that was sighted and photographed on the 28 March 2016 at $11: 05 \mathrm{~h}$ at Madhabkunda Eco-park $\left(24.6403^{\circ} \mathrm{N}\right.$, $92.2280^{\circ} \mathrm{E}$; WGS 84 ) in Bangladesh. The habitat of the park is composed of mixed-evergreen tree species with several streams. The observed $C$. versicolor was seen basking on the ground. Photographs were taken promptly and the lizard was then caught with the aid of a butterfly sweep net without apparently causing any injuries. The specimen was $345 \mathrm{~mm}$ (snout-vent length: $70 \mathrm{~mm}$, tail length: $275 \mathrm{~mm}$ ) and showed clear signs of physical malformations (Fig. 1B). The trunk was highly deformed with two humps at the beginning of the thorax and the end of the pelvic region. Both forelimbs and hindlimbs seemed to be without any deformities. The tail also showed obvious malformations; it was stiff and spirally twisted along its entire length. After taking measurements, the specimen was released at its original location and it later left the area - showing no difficulties in locomotion. On the same day, we found four more specimens of $C$. versicolor that were all of normal physical appearance.

We could not collect or preserve the specimen for further investigations as we had no legal permits to collect specimens at that time, which makes it impossible to postulate a definite cause of the malformations. Ideally, the animal should have been radiographed in order to determine the exact nature of its vertebral developmental abnormality. The gross appearance strongly suggests that this was kyphosis (an abnormally excessive convex curvature of the vertebral column) but, without radiographs or dissection, concurrent scoliosis (the vertebral column twists and curves laterally) and/or lordosis (an abnormally excessive inward curvature of the vertebral column) cannot be excluded.

For many decades, developmental abnormalities have been recognised in captive and to a lesser extent freeliving reptiles. A seminal work, which helped define and categorise such abnormalities including those involving the vertebral column, was provided by Bellairs (1981). Recent descriptions of anomalies in free-living lizards include the report by Gehring (2009) of an apparently similarly deformed chameleon, Furcifer pardalis from north-eastern Madagascar. Arrivillaga \& Brown (2019) reported kyphosis in a free-living Skink Marisora brachypoda from Utila Island, Honduras. Hindlimb deformities were also observed in a Brown anole, Anolis sagrei from Taiwan (Norval et al., 2009).

Bellairs (1981) stated that developmental abnormalities of reptiles are essentially of either genetic or environmental origin. The latter can be particularly significant, especially incubation of reptile eggs at excessively low or high temperatures and low relative humidity. Biochemical substances specifically, toxins and pollutants might be responsible for some of the malformations observed in reptiles in the wild (Bellairs, 1981). Other causes that might trigger malformation in reptiles include inbreeding of reptile populations with low genetic diversity (Madsen et al., 1992; Olsson et al., 1996; Norval et al., 2009).

\section{ACKNOWLEDGEMENTS}

We are thankful to local guides who accompanied us during the survey. Special thanks and gratitude to Dr John E. Cooper, and K.M. Mijanur Rahman for their valuable comments on the manuscript. 


\section{REFERENCES}

Arrivillaga, C. \& Brown, T. (2019). Kyphosis in a free-living Marisora brachypoda (Squamata: Scincidae) from Utila Island, Honduras. Herpetological Bulletin 148: 43-44.

Bellairs, A. d'A. (1981). Congenital and developmental diseases. In: Diseases of the Reptilia. Eds Cooper, J.E. and Jackson, O.F., pp. 469-485. Academic Press, London.

Das, I. (2010). A Field Guide to the Reptiles of South-East Asia. New Holland Publishers (UK) Ltd., London. 376 pp.

Gehring, P. S. (2009). A remarkable case of malformation in a free-living individual of Furcifer pardalis (Cuvier, 1829) from northern Madagascar. Herpetology Notes 2: 223225.

Hasan, M.K., Khan, M.M.H. \& Feeroz, M.M. (2014). Amphibians and Reptiles of Bangladesh - A Field Guide. Arannayk Foundation, Dhaka, Bangladesh. 191 pp.

IUCN Bangladesh. (2015). Red List of Bangladesh. Volume 4. Reptiles and Amphibians. Dhaka, Bangladesh, IUCN Bangladesh Country Office. 337 pp.

Khan, M.A.R. (2015). Wildlife of Bangladesh: Checklist-cumguide. Chayabithi publications, Dhaka, Bangladesh. 568 pp.
Khan, M. M. H. (2008). Protected Areas of Bangladesh-A Guide to Wildlife. Nishorgo Support Program, Bangladesh Forest Department, Dhaka, Bangladesh. 223 pp.

Madsen, T., Shine, R., Loman, J. \& Håkansson, T. (1992). Why do female adders copulate so frequently? Nature 355 : 440-441.

Norval, G., Mao, J.-J., Bursey, C.R. \& Goldberg, S.R. (2009). A deformed hind limb of an invasive free-living brown anole (Anolis sagrei Duméril \& Bibron, 1837) from Hualien City, Taiwan. Herpetology Notes 2: 219-221.

Olsson, M., Gullberg, A. \& Tegelström, H. (1996). Malformed offspring, sibling matings, and selection against inbreeding in the sand lizard (Lacerta agilis). Journal of Evolutionary Biology 9: 229-242.

Uetz, P., Freed, P. \& Hošek, J. (eds.). (2019), Calotes versicolor. The Reptile Database, http://www.reptile-database.org, Accessed on 17 September 2018.

Accepted: 9 April 2020 